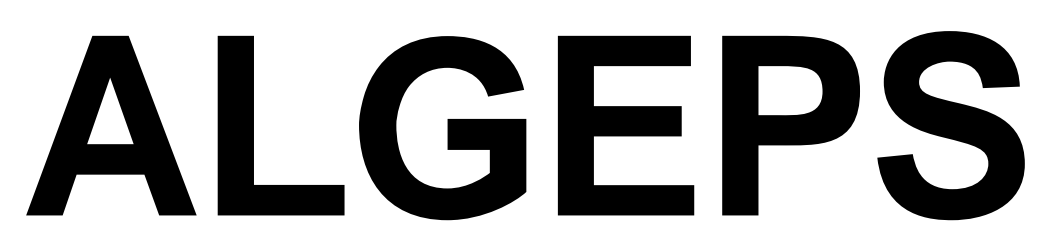

REVISTA DE GEOLOGIA, SÈRIE B no 600 - Agost del 2012

ISSN $1132-7014$

D.L.B. 28.178 - 92

13 pàgines

\title{
RECORRIDO DESDE SABIÑÁNIGO A BIESCAS Y A PANTICOSA, CON UNA HIJUELA A PIEDRAFITA, A TRAVÉS DEL PATRIMONIO GEOLÓGICO Y MINERO DE LAS COMARCA DEL ALTO GÁLLEGO
}

Josep M. Mata-Perelló

Aquest recorregut va ésser experimentat amb docents el dia 1 DE SETEMBRE DEL 2010 


\section{RECORRIDO DESDE SABIÑÁNIGO A BIESCAS Y A PANTICOSA, CON UNA HIJUELA A PIEDRAFITA, A TRAVÉS DEL PATRIMONIO GEOLÓGICO Y MINERO DE LAS COMARCA DEL ALTO GÁLLEGO}

\section{ADVERTENCIAS PREVIAS}

Como en otros recorridos de RECONOCIMIENTO GEOLÓGICO (o de RECONOCIMIENTO GEOLÓGICO Y MINERO), el recorrido se compondrá de diversas PARADAS. En este caso serán ocho.

Por otra parte, habrá que tener en cuenta, en todo momento, especialmente antes de empezar los recorridos de los diferentes tramos, el estado de los caminos y carreteras, por donde transitará el recorrido. Al respecto, cabe decir que prácticamente todos estos tramos se halla en buenas condiciones.

Finalmente, como ya hacemos en otros recorridos similares, queremos decir que hace falta tener un cuidado muy especial en el respeto a la naturaleza, a lo largo de todo el recorrido del itinerario, y también fuera de él.

\section{BREVE INTRODUCCIÓN GEOLÓGICA}

El recorrido de este itinerario, se desarrollará por una de las tres unidades geológicas que constituyen el suelo y el subsuelo de Aragón. Concretamente por el Sistema Pirenaico, Cordillera Pirenaica o simplemente Pirineos. Dentro de esta unidad, el recorrido se iniciará en el denominado Pirineo Meridional, por el cual se transitará entre Sabiñánigo y las inmediaciones de Escarrilla. Luego, el recorrido entrará plenamente en la Zona Axial Pirenaica, en donde finalizará.

Así, a lo largo de todo de todo el recorrido del primer tramo del itinerario, se irán encontrando afloramientos de los materiales del Cenozoico (fundamentalmente del Eoceno y del Oligoceno). Ello ocurrirá entre Sabiñánigo y las inmediaciones del Puente de Santa Elena. Más adelante, entre ese lugar acabado de mencionar y las inmediaciones de Escarrilla, ya encontraremos afloramientos del mesozoico (fundamentalmente del Cretácico), también dentro del Pirineo Meridional. Y finalmente, en los últimos tramos. Dentro de la Zona Axial Pirenaica, encontraremos afloramientos de los materiales paleozoicos (del Ordovícico, Silúrico, Devónico y Carbonífero.

\section{BREVE INTRODUCCIÓN GEOGRÁFICA}

El recorrido del presente itinerario se efectuará casi exclusivamente por una comarca aragonesa, la del Alto Gállego. Así, se iniciará en la propia capital comarcal, 
en la ciudad de Sabiñánigo. Luego, el recorrido se dirigirá hacia el Norte, pasando por los municipios de Biescas, Sallent de Gállego y Panticosa (en donde finalizará el recorrido del itinerario).

Por otra parte, cabe decir que esta comarca, gravita en torno al río Gállego, tributario del Ebro. Este río recoge las aguas de toda la comarca. En este recorrido también transitaremos por el valle del río de Panticosa, tributario del Gállego

\section{OBJETIVOS GENERALES DE ESTE ITINERARIO}

En este itinerario, los objetivos generales que se han de conseguir, se pueden concretar en los siguientes aspectos:

1.- Estudio y reconocimiento de los materiales cenozoicos (fundamentalmente del Eoceno y del Oligoceno) situados en los Pirineos Meridionales, que iremos encontrando a lo largo del recorrido del itinerario, entre las inmediaciones de las poblaciones de Sabiñánigo y de Biescas.

2.- Estudio y reconocimiento de los materiales mesozoicos (fundamentalmente del Cretácico) situados en los Pirineos Meridionales. Estos materiales los iremos encontrando desde el Puente de Santa Elena hasta las inmediaciones de Escarrilla.

3.- Estudio y reconocimiento de los materiales paleozoicos (fundamentalmente del ordovícico, Silúrico, Devónico y Carbonífero) situados en la Zona Axial Pirenaica. Estos materiales los iremos encontrando desde Escarrilla hasta Panticosa.

4.- Estudio y observación de la estructura de los Pirineos, en los tramos concernientes al recorrido.

5.- Visión de algunas de las antiguas explotaciones encontradas a lo largo del recorrido del itinerario. En concreto de diversas explotaciones de grava, situadas en el municipio de Sabiñánigo).

6.- Observación del impacto producido por las actividades mineras. I de las restauraciones realizadas para paliar este impacto.

7.- Observación de los fenómenos termales y de los establecimientos relacionados con ello. Los veremos en los Baños de Panticosa.

8.- Visión de los diferentes lugares directamente relacionados con el Patrimonio Geológico y Minero que iremos encontrando a lo largo del recorrido del presente itinerario.

\section{ANTECEDENTES BIBLIOGRÁFICOS}

En relación con este itinerario, no conocemos ningún antecedente, relativo a otro itinerario que discurra por este lugar. En este sentido, este itinerario ya constituye un antecedente, si no estamos equivocados. 
Por otra parte, tenemos otros antecedentes nuestros, en relación a las mineralizaciones presentes en esta zona. Se trata de MATA-PERELLÓ (1987, 1990), dedicados a las mineralizaciones de Aragón y de esta comarca, respectivamente.

En relación con las características del patrimonio geológico citaremos el trabajo publicado por la GADMA (2001), así como el de CARCAVILLA et altri (2006).

Todos estos trabajos se hallaran debidamente relacionados en el apartado de REFERENCIAS BIBLIOGRÁFICAS, que figura al final del presente trabajo

\section{RECORRIDO DEL ITINERARIO}

Indicaremos, a continuación el posible recorrido del itinerario, el cual discurriría por diferentes lugares de la comarca anteriormente citada. Así, el recorrido se iniciará en la ciudad de Sabiñánigo, por donde se efectuará la primera parada. Tras ello se dirigirá hacía Senegüé, Arguisal, Escuer y Biescas, sin realizar ninguna parada en este tramo, hasta la última población. Este recorrido se efectuará por la carretera A - 136 / N -260. Luego, se efectuará una hijuela por la carretera de Aso de Sobremonte, por donde efectuaremos una nueva parada.

Tras ello, el recorrido seguirá hacía el norte, ahora por la carretera A - 136. Al pasar por el Puente de Santa Elena se efectuará una nueva parada, continuando luego hacía el Norte. Al encontrar el ramal que conduce a Piedrafita de Jaca, nos convendrá tomarlo, para ir a ese pueblo. Y luego a la zona del Ibón de Piedrafita, en donde haremos dos nuevas paradas.

Tras retornar a la carretera A - 136, seguiremos hacía el Norte, hasta las inmediaciones de Escarrilla, desde donde iremos a Panticosa, en donde efectuaremos la última parada del recorrido.

\section{DESCRIPCIÓN DEL ITINERARIO}

Como de costumbre, estructuraremos el recorrido del itinerario en una serie de PARADAS, que a continuación iremos viendo. En cada una de estas paradas haremos un breve comentario (geológico o mineralógico, según acontezca). Por otra parte, en cada caso indicaremos (entre paréntesis) la hoja topográfica en donde se halla la parada. Para ello, utilizaremos las hojas del Instituto Geográfico y Catastral de España, publicadas a la escala de 1:50.000. En este caso, solo utilizaremos dos hojas, las siguientes: 145 (o de Sallent de Gállego) y 177 (Biescas).Así pues, la relación de las paradas que componen el recorrido de este itinerario, son las siguientes:

PARADA 1. GRAVERA DE SABIÑ́ANIGO, (término municipal de Sabiñánigo, comarca del Alto Gállego). (Hoja 177).

Después de efectuar el inicio del recorrido en la población de Sabiñánigo, nos convendrá tomar el ramal que conduce directamente a la carretera que enlaza Sabiñánigo 
con Biescas, la carretera autonómica A - 136 (actual N - 260). Al llegar al cruce con la carretera de Larrés. Ahí haremos la primera parada del recorrido de este itinerario, a unos 2 Km de Sabiñánigo.

En este recorrido, habremos ido encontrando afloramientos de los materiales cenozoicos que forman parte del Pirineo Meridional. Entre estos materiales predominan los tramos de turbiditas y de calcolutitas de intenso color gris - azulado, como puede verse entorno del lugar en donde haremos esta parada.

En este lugar hay las instalaciones de una planta de tratamiento de áridos. Ahí se tratan los materiales extradós en diferentes graveras de la zona, fundamentalmente de las terrazas fluviales del río Géllego.

Esta plata, actualmente en activo (mediados del 2010), constituye una de las actividades mineras más importantes de la comarca del Alto Gállego. Por otra parte, para poder visitar esta instalación es conveniente pedir la correspondiente autorización a la empresa minera, a HORMYAPA, S.A.

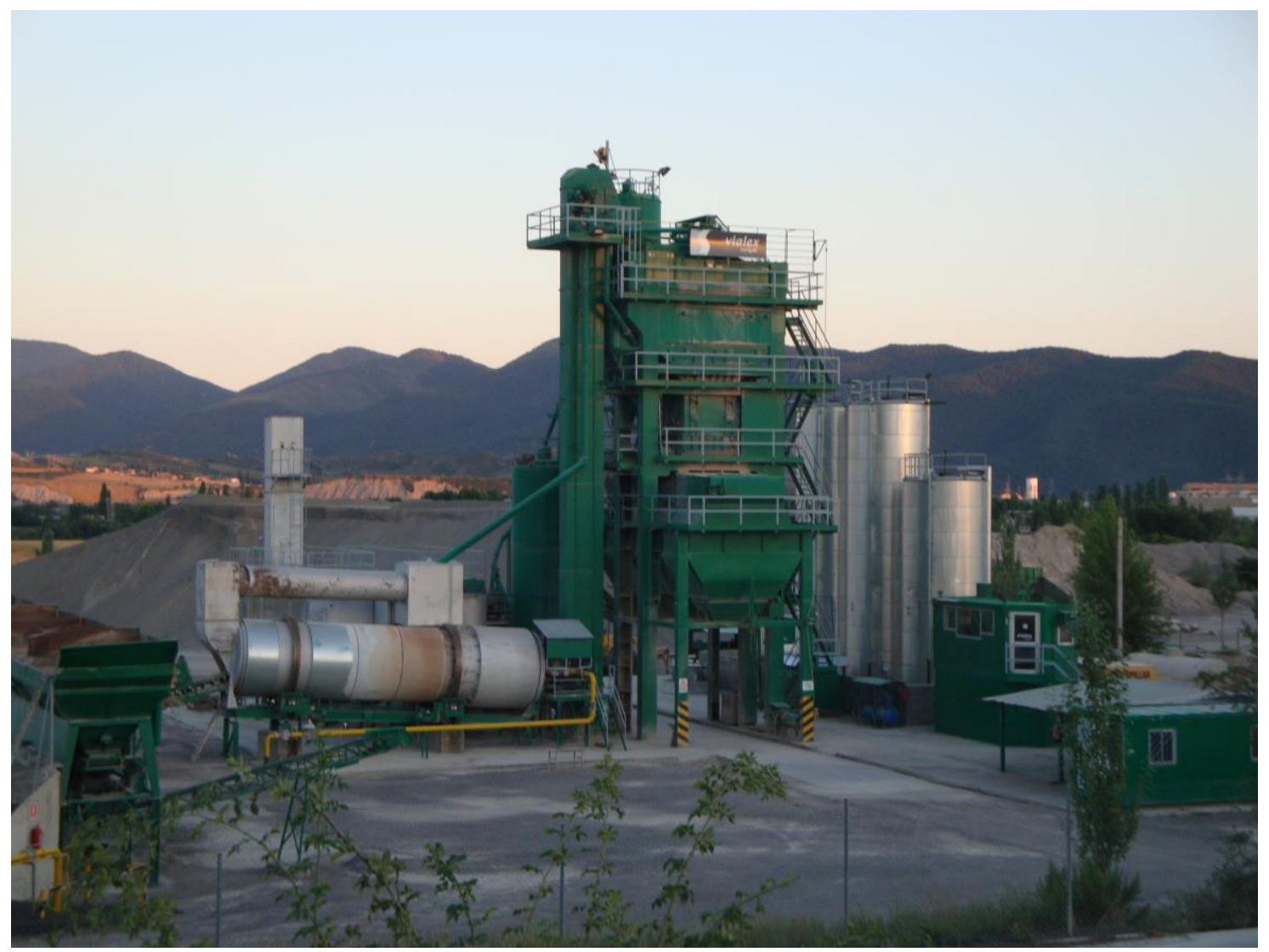

Planta de tratamiento de áridos

PARADA 2. ANTIGUO CAMPING DE BIESCAS, (término municipal de Biescas, comarca del Alto Gállego). (Hoja 177).

Tras realizar la parada anterior, cabe continuar hacía el Norte por la carretera de doble denominación, la A - 136 / N - 260. Por esta carretera pronto pasaremos por 
Senegüé y más adelante por Arguisal. Luego llegaremos a Escuer (o Casas de Escuer). Y finalmente a Biescas. A la entrada de la población, por la izquierda de la carretera, pasaremos por el lugar en donde estuvo el Camping de Biescas. Ahí podemos hacer una nueva parada, a unos $15 \mathrm{Km}$ de la anterior.

En este recorrido, habremos ido encontrando los materiales cenozoicos, cada vez más detríticos. Estos materiales del Eoceno (fundamentalmente) son los que conforman el Pirineo en donde ahora estamos situados.

En este lugar ocurrió hace unos años una gran tragedia. Ello fue motivado por la correntada que bajó hacía el camping a través del barranco de Aso (y de su afluente, el barranco de la Selva). Las aguas y la carga sólida por ellos transportada, cayeron sobre el camping, destrozándolo. Cabe decir que, lamentablemente éste se había instalado en un lugar incorrecto, desoyendo las recomendaciones de los geólogos.

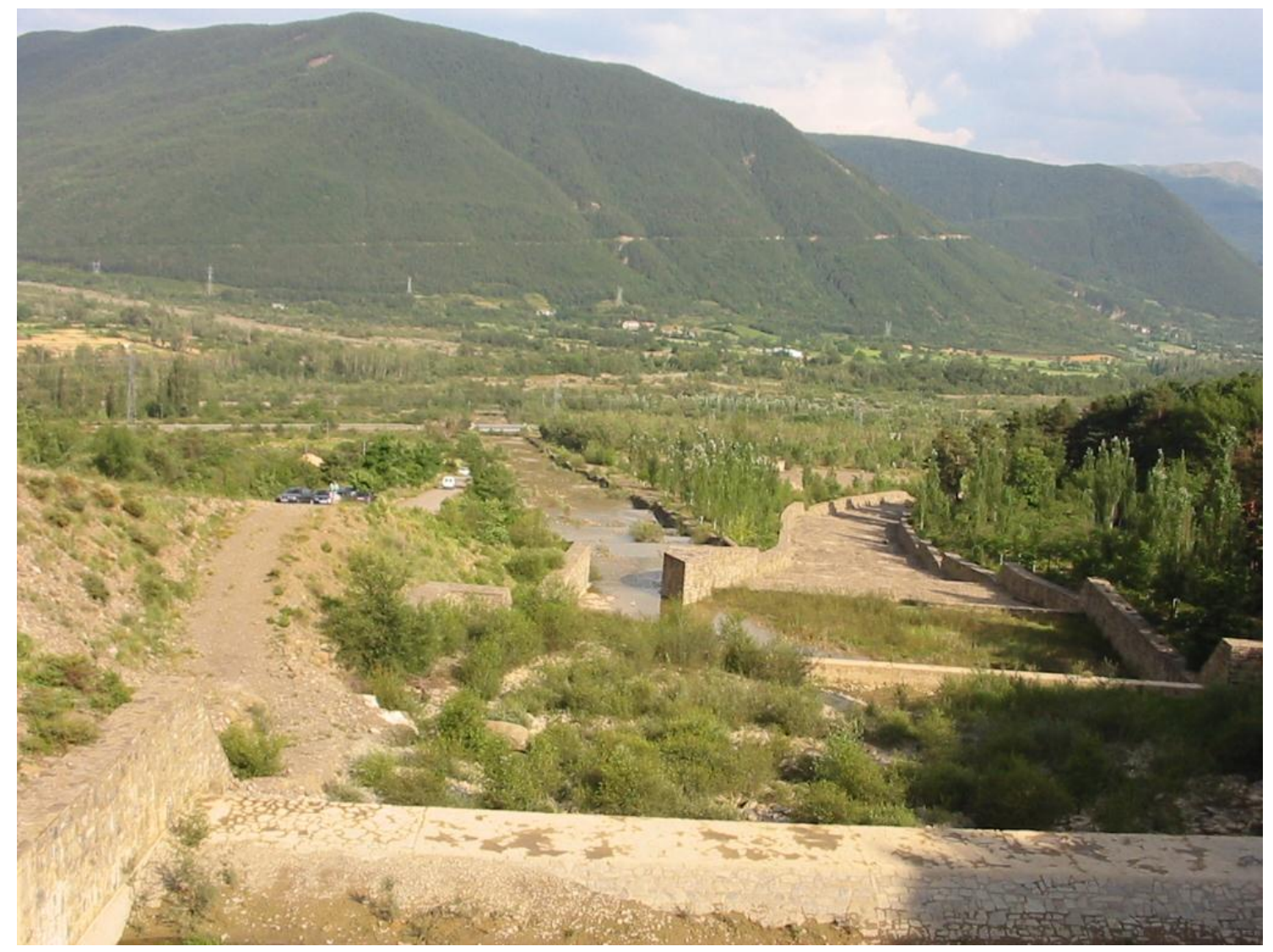

Lugar es donde estaba el Camping de Biescas, con el barranco ahora canalizado

PARADA 3. LAS SEÑORITAS DE ARAS, (término municipal de Biescas, comarca del Alto Gállego). (Hoja 177).

Después de realizar la parada anterior, cabe continuar hacía el Norte por la carretera, que a partir de ahora solo tendrá una denominación (la A - 136). Poco después de dejar la población de Biescas, encontraremos una carretera que conduce a Aso de Sobremonte. Nos convendrá cogerla. A unos 3 - 4 Km encontraremos una indicación que 
nos conducirá por un camino de tierra, hacía el mirador de las Señoritas de Aras. Ahí efectuaremos una nueva parada, tras recorrer unos $4 \mathrm{Km}$, aproximadamente, desde la parada anterior.

En este recorrido habremos ido encontrando los materiales citados en los recorridos anteriores. Estos materiales cenozoicos, pertenecen fundamentalmente al Eoceno, y forman parte del Pirineo en este sector; concretamente del denominado Pirineo Meridional, en donde estamos ahora situados.

En este recorrido, junto a la carretera, habremos visto unas estructuras sedimentarias que afectan a los materiales acabados de mencionar, a las turbiditas y a las calcolutitas grisáceas.

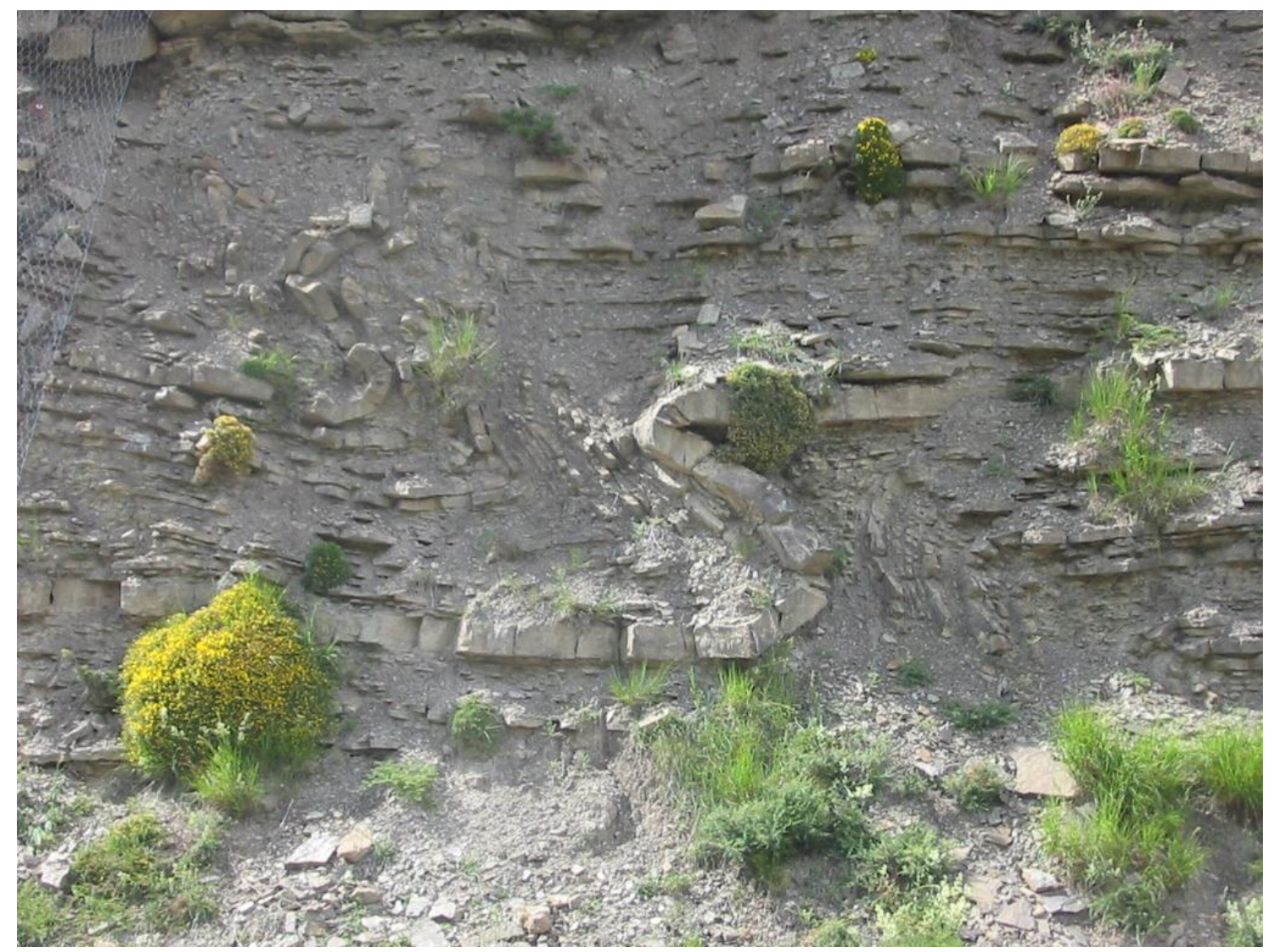

Un pliegue sinsidementario entre los materiales eocénicos

Más adelante, al llegar a la zona de la parada, podremos divisar perfectamente las denominadas Señoritas de Aras. Se trata de unas "chimeneas de hadas", formadas a partir de los materiales detríticos del barranco de Aso, del que hemos hablado anteriormente en la parada efectuada antes en Biescas. Cabe decir que a este lugar podíamos haber llegado directamente desde abajo, remontando el barranco desde el Camping de Biescas, a través de los caminos que se hicieron en su momento para canalizar este barranco. De haber subido por él, hubiéramos visto las presas que se construyeron hace unos años, tras la tragedia que arraso el camping. 
Por lo que concierne a las Señoritas de Aras, cabe decir que constituyen un elemento importante del patrimonio geológico de esta comarca, y del conjunto de los Pirineos Aragoneses.

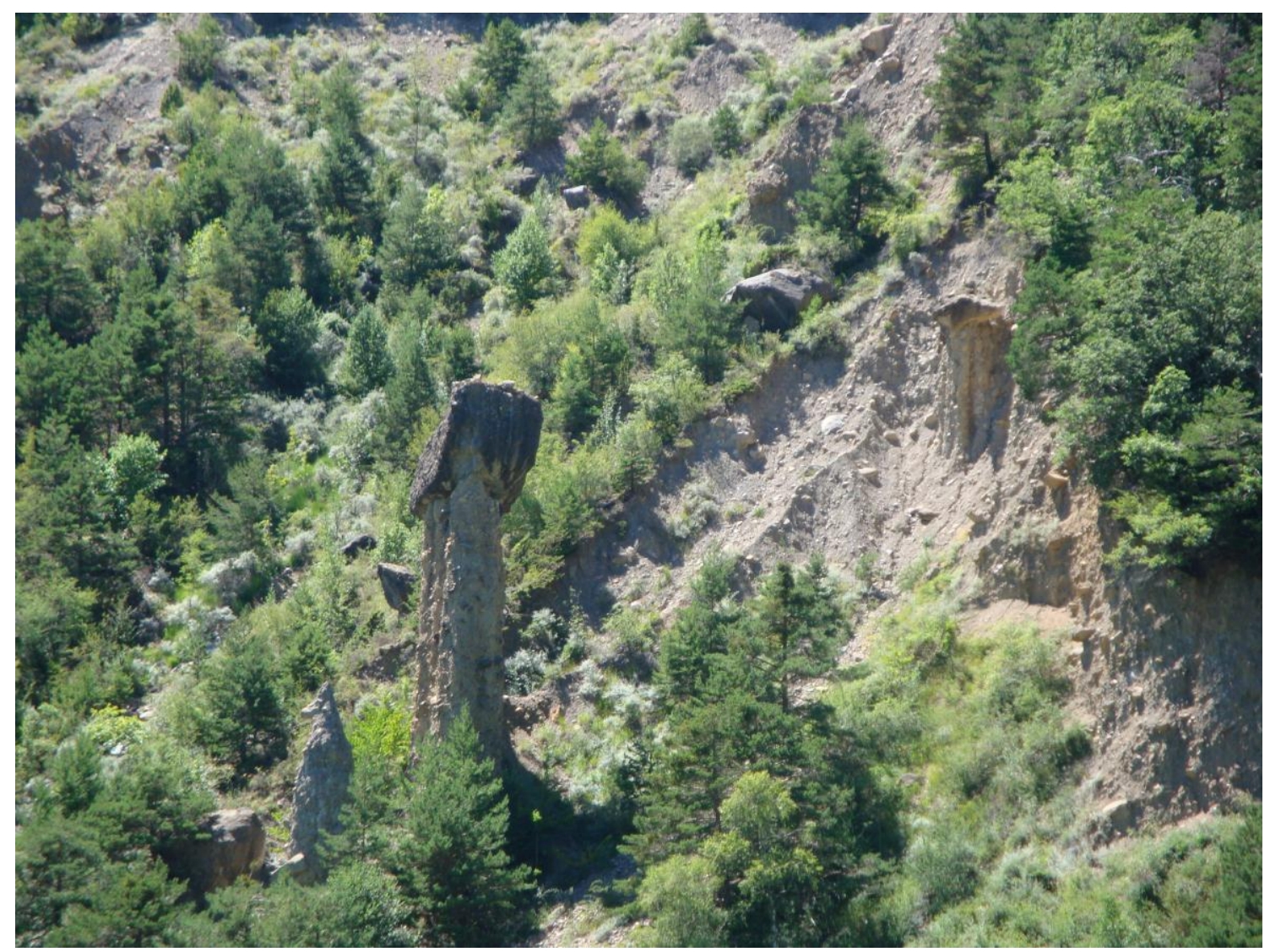

Las Señoritas de Aras

PARADA 4. PUENTE DEL MONASTERIO DE SANTA ELENA, (término municipal de Biescas, comarca del Alto Gállego). (Hoja 177).

Tras realizar la parada anterior, conviene retroceder hasta la carretera A - 136, dando por finalizada la hijuela que nos ha llevado hasta la parada anterior. Al encontrar de nuevo la carretera mencionada, nos convendrá continuar por ella hacía el Norte. Más adelante, al encontrar los carteles indicativos que señalizan el Monasterio de Santa Elena, nos convendrá parar junto a la carretera, para ir a pie hasta el cercano puente sobre el río Gállego (unos 50 metros escasos). Ahí, efectuaremos una nueva parada, a unos $6 \mathrm{Km}$ de la realizada anteriormente.

En este recorrido, habremos ido encontrando afloramientos de los materiales cenozoicos que hemos visto en las paradas anteriores. Estos materiales cenozoicos, del Eoceno, están constituidos por tramos de turbiditas y calcolutitas de tonalidad grisáceas. Ellos forman parte de los denominados Pirineos Meridionales.

Sin embargo, al llegar al sector de la parada, habremos encontrado afloramientos eminentemente carbonatados de materiales que pertenecen al Paleoceno - Eoceno, y más 
adelante al Cretácico. Es decir, habremos entrado en los afloramientos mesozoicos de los Pirineos Meridionales.

Y, precisamente, en este sector el río Gállego ha construido un estrecho al atravesar estos materiales. Este es el sector en donde ahora estamos, en el puente de la carretera que conduce al Monasterio.

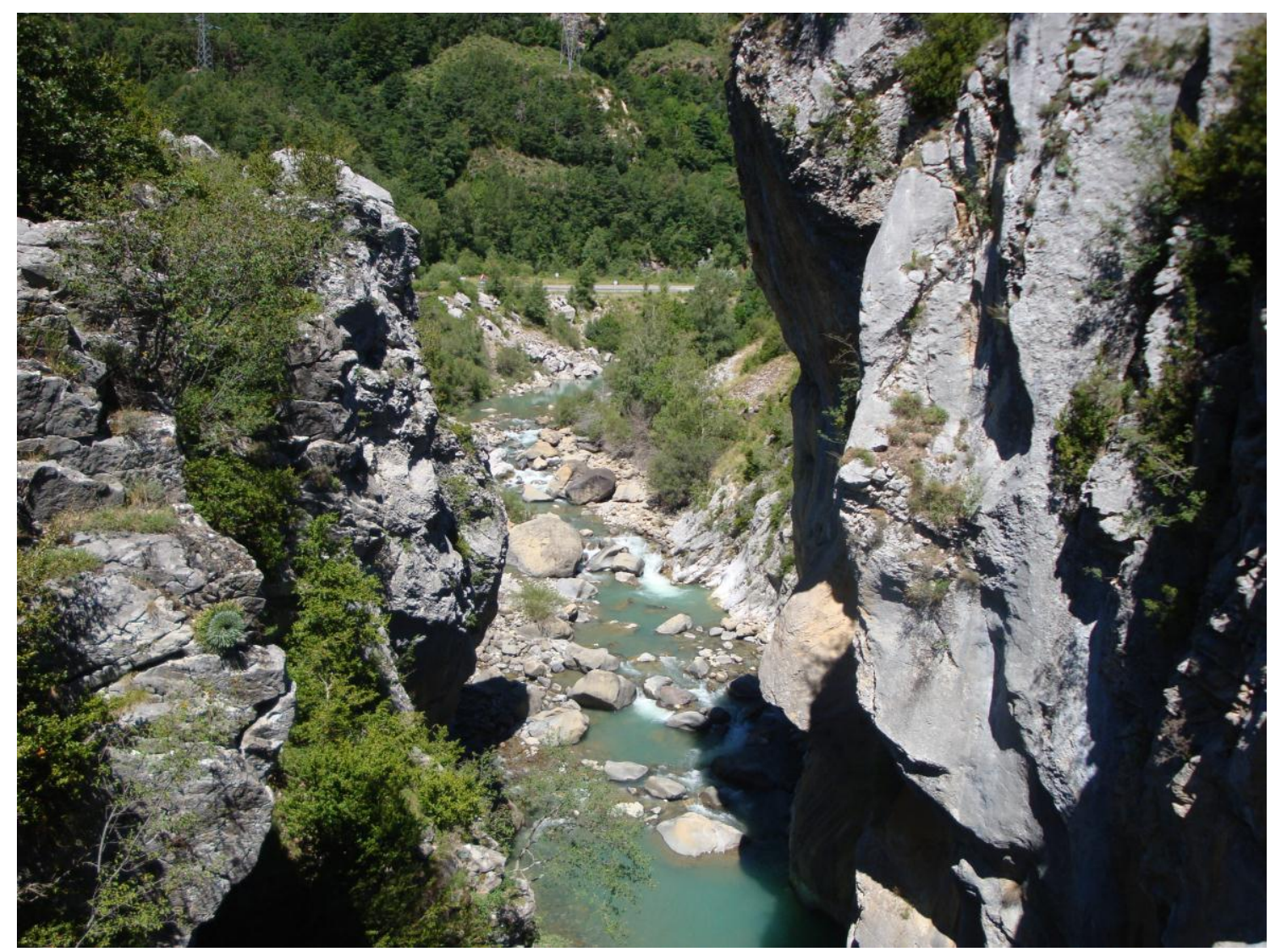

El estrecho del puente del Monasterio de Santa Elena

Cabe decir, que subiendo hasta el citado monasterio, y luego descendiendo hasta el río por un sendero, tendremos ocasión de llegar hasta los conocidos Travertinos de Santa Elena (PARADA 4 - BIS). Estos travertinos constituyen un elemento importante del patrimonio geológico del Alto Gállego.

PARADA 5. EL IBÓN DE PIEDRAFITA, (Piedrafita de Jaca, término municipal de Biescas, comarca del Alto Gállego). (Hoja 145).

Después de realizar la parada anterior, cabe continuar hacía el Norte por la carretera, (la A - 136). Por ella pasaremos pronto por el despoblado de Burbal, llegando más adelante al cruce de donde parte la carretera que conduce hacía Piedrafita de Jaca. Así, nos convendrá ir hacía esta población, iniciando una larga hijuela. Luego, al llegar al pueblo, continuaremos por la pista hacía el Ibón de Piedrafita, a pie, ya que la pista está cortada. Tras caminar unos $3 \mathrm{Km}$ llegaremos al ibón. Ahí efectuaremos una nueva parada, a unos $8 \mathrm{Km}$ de la parada anterior. 
En este recorrido, habremos ido encontrando afloramientos de los materiales mesozoicos, de los que hemos mencionado en el trayecto de la parada anterior. Estos materiales son fundamentalmente carbonatados, con calizas, calcarenitas y dolomías, pertenecientes al Cretácico.

Más adelante, se llegará al ibón de Piedrafita, cabe decir que éste constituye un buen ejemplo de lago de montaña, de origen glacial. Además del interés que encierra, su situación es inmejorable bajo la Peña Telera, en donde puede observarse un cabalgamiento entre los materiales del Cretácico y los del Paleoceno - Eoceno. Sobre esta misma mole carbonatada, en el sector septentrional, puede observarse una interesante fractura, que afecta a unos niveles carbonatados del Cretácico.

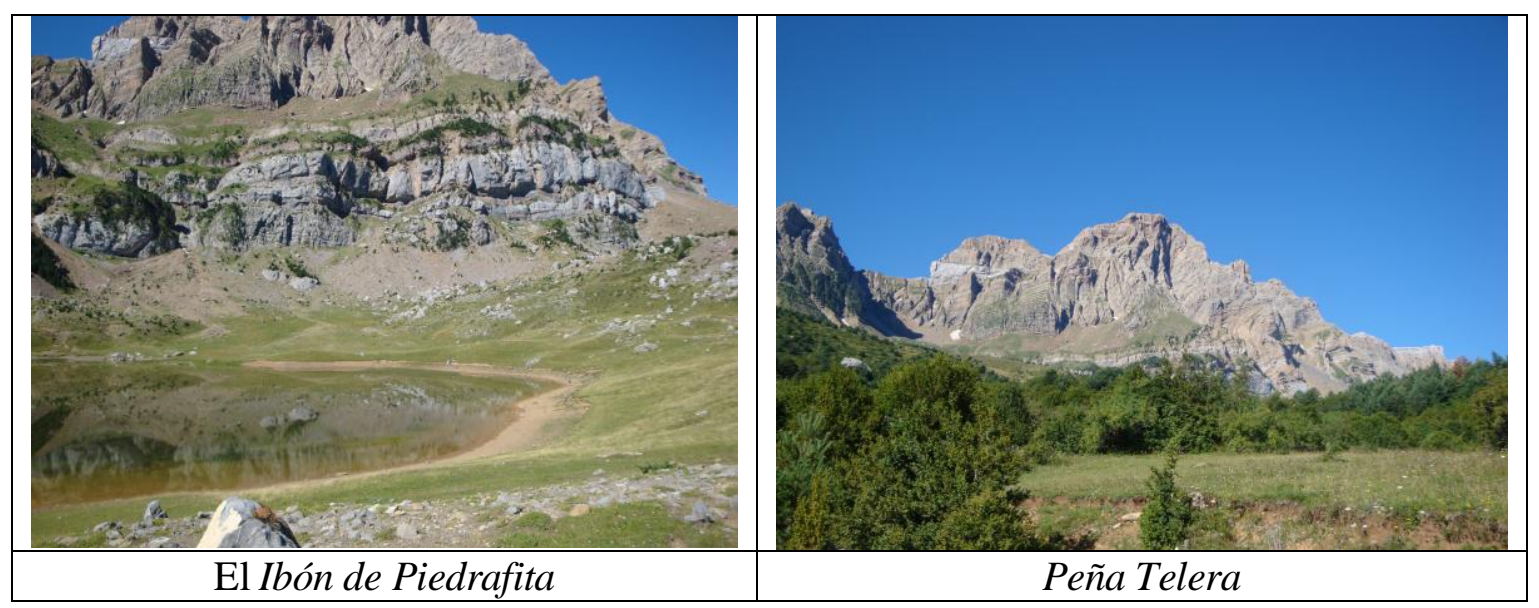

PARADAS 6. EL KARTS DEL CAMPANAL, (Piedrafita de Jaca, término municipal de Biescas, comarca del Alto Gállego). (Hoja 145).

Tras realizar la parada anterior, cabe efectuar un breve recorrido a pie, de menos de $1 \mathrm{Km}$, hacía el Sur del ibón. Así se llegará a una zona más o menos deprimida, en donde efectuaremos una nueva parada.

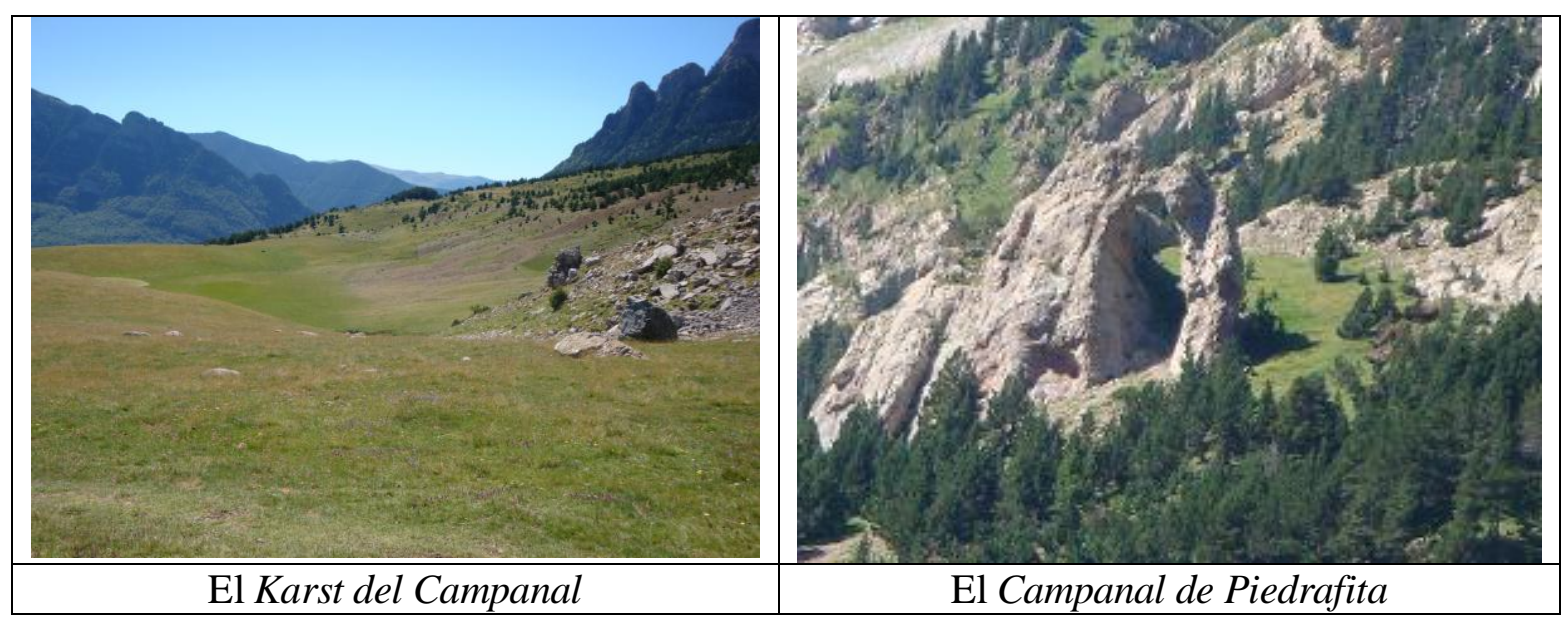


En este recorrido habremos ido encontrando afloramientos de los materiales mesozoicos citados en la parada anterior. Estos materiales son eminentemente carbonatados y sobre ellos se ha desarrollado un interesante karts. Así, es fácil ver varias dolinas en este sector. Asimismo, en algunos sectores será sencillo ver un interesante caos kárstico. Por otra parte, mirando al Oeste desde la zona kársticas, es factible ver el denominado Campanal de Piedrafita. Se trata de una forma de erosión, que ha horadado una ventana entre los afloramientos carbonatados mesozoicos de la Sierra de Pantacua, en los sectores más orientales de la misma.

Estos dos elementos, forman parte del patrimonio geológico de la comarca del Alto Gállego, especialmente el segundo.

PARAdA 7. CARRETERA AL PUEYO DE JACA, (el Pueyo de Jaca, término municipal de Panticosa, comarca del Alto Gállego). (Hoja 145).

Tras realizar la parada anterior, conviene retroceder hasta la carretera A - 136, deshaciendo la hijuela iniciada anteriormente. Luego, convendrá seguir por la carretera A 136., hasta casi llegar a Escarrilla. Sin embargo, continuaremos por la carretera que se dirige a Panticosa, la A - 2606, hasta encontrar el cruce del Pueyo de Jaca, que tomaremos inicialmente. Poco después haremos una nueva parada, a unos $12 \mathrm{Km}$ de la anteriormente realizada

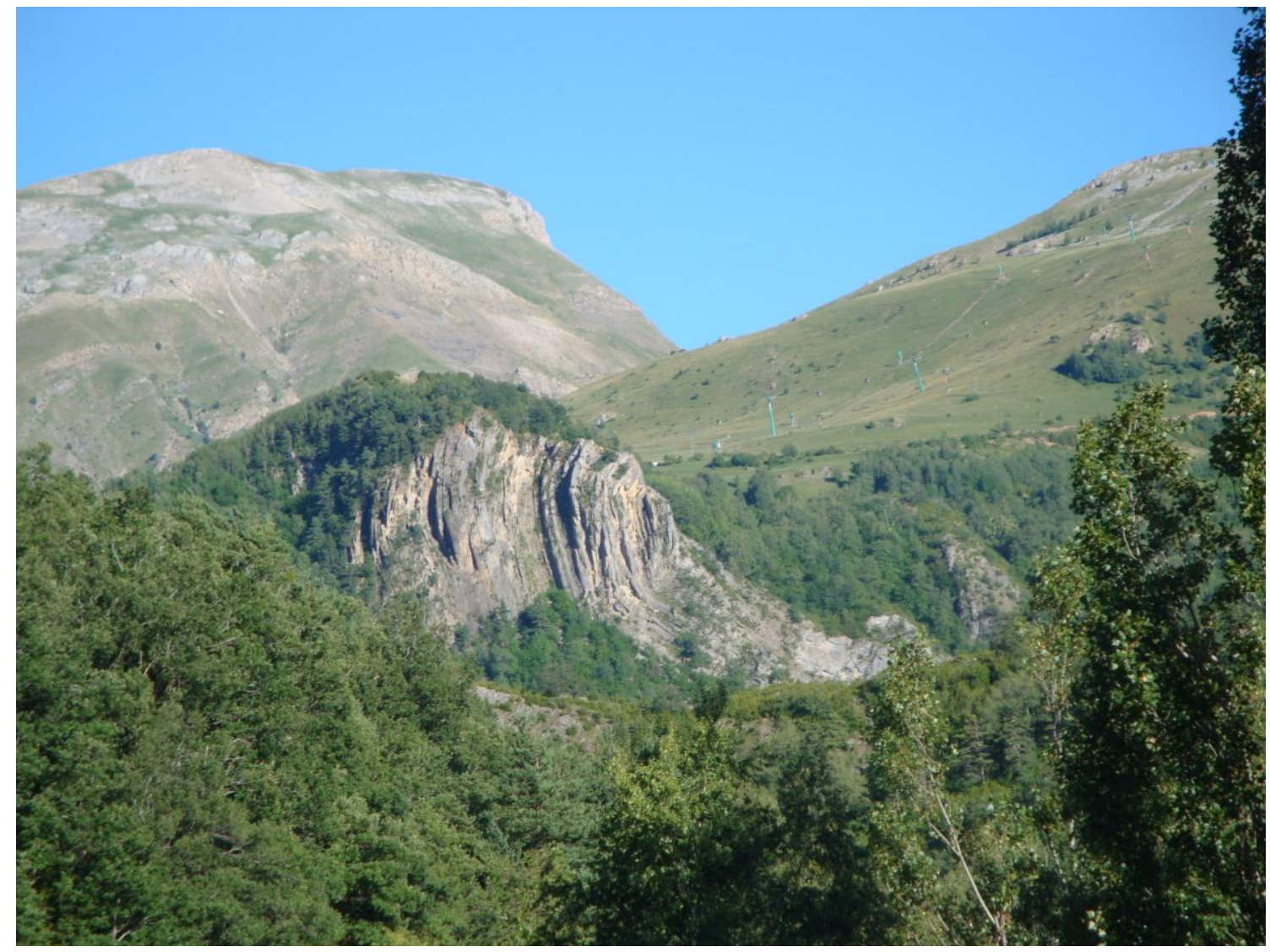

El Sinclinal del Pueyo y de Panticosa 
En este recorrido habremos vuelto a encontrar los materiales mesozoicos mencionados en las paradas anteriores y en los trayectos anteriores. Estos materiales pertenecen mayoritariamente al Cretácico.

Desde este lugar es posible ver el flanco de un sinclinal (el Sinclinal del Pueyo Panticosa), que hemos reproducido en la fotografía anterior. Esta interesante estructura se halla sobre un afloramiento de los niveles carbonatados del Devónico, ubicándose dentro de la Zona Axial Pirenaica.

PARADA 8. LOS BAÑOS DE PANTICOSA, (Baños de Panticosa, término municipal de Panticosa, comarca del Alto Gállego). (Hoja 145).

Tras efectuar la parada anterior, cabe retornar a la carretera A - 2606, con la finalidad de llegar primero a Panticosa y posteriormente a los Baños de Panticosa. En este lugar efectuaremos una nueva parada, la última de este itinerario, a unos $10 \mathrm{Km}$ de la anteriormente efectuada.

En este recorrido, habremos encontrado afloramientos de los materiales paleozoicos de la Zona Axial Pirenaica, entre los que predominan los materiales carbonatados del Devónico. Al llegar al balneario, entorno a él, habremos encontrado afloramientos graníticos.

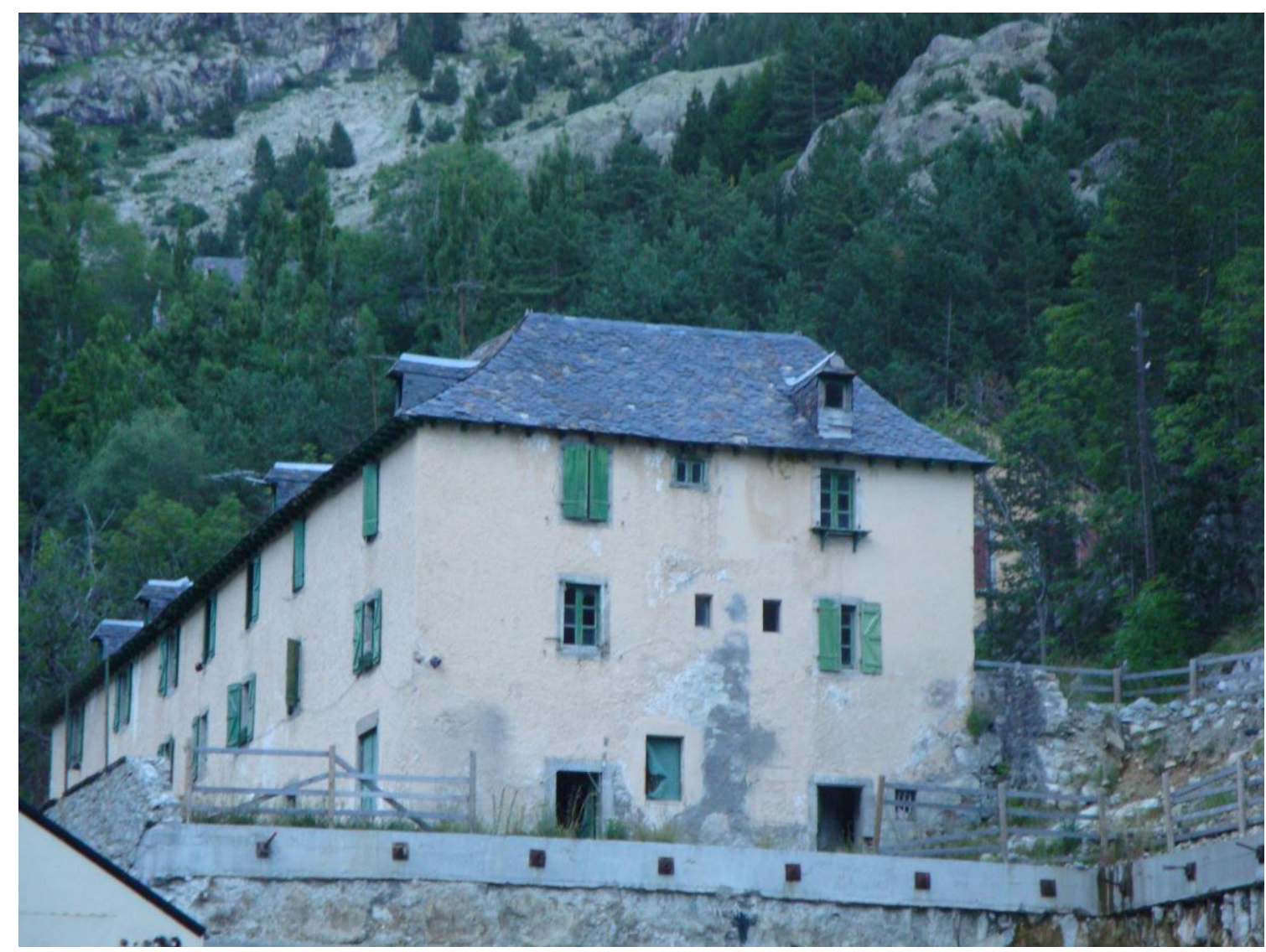

Las instalaciones del Balneario viejo de Panticosa 
Al llegar al Balneario de Panticosa, habremos encontrado el Ibón de Pantcosa, notablemente recrecido con una represa. Y más adelante, habremos visto las instalaciones nuevas y las viejas del balneario. Por lo que concierne a estas últimas, cabe decir que forman parte del patrimonio minero de la comarca del Alto Gállego.

\section{EN ESTE LUGAR FINALIZA EL RECORRIDO DEL PRESENTE ITINERARIO}

\section{BIBLIOGRAFIA}

CALVO, M. Et altri (1988).- Minerales de Aragón. Colección: temas geológicos, Edit. Mira, 210 Pág. Zaragoza

GADMA. (2001).- Puntos de Interés Geológico de Aragón, Edit. Gobierno de Aragón, Departamento de Medio Ambiente (GADMA). 243 Pág. Zaragoza

MAESTRE, A. (1845).- Descripción geognóstica del Distrito Minero de Aragón y Cataluña. Anales de Minas, t. III, Madrid

MATA-PERELLÓ, J.M. (1987).- Introducción al conocimiento de las mineralizaciones aragonesas. Mineralogistes de Catalunya, t.III, pp. 258-265. Barcelona

MATA-PERELLÓ, J.M. (1990).- Inventario Mineralógico de la comarca del Sarrablo. Rodeno, nº 16. 20 Pág. Manresa

PRAMES (2005).- Alto Gállego. Colección RUTASCAL por Aragón. Prames, Gobierno de Aragón. 119 Pág. Zaragoza. 